\title{
Balancing processing ease with combustion performance in aluminum/PVDF energetic filaments
}

\author{
Matthew C. Knott ${ }^{1}$, Ashton W. Craig ${ }^{1}$, Rahul Shankar ${ }^{2}$, Sarah E. Morgann',b), Scott T. Iacono ${ }^{3}$, \\ Joseph E. Mates ${ }^{4}$, Jena M. McCollum ${ }^{1, a)}$ \\ ${ }^{1}$ University of Colorado Colorado Springs, Department of Mechanical and Aerospace Engineering, Colorado Springs, Colorado 80918, USA \\ ${ }^{2}$ University of Southern Mississippi, School of Polymer Science and Engineering, Hattiesburg, Mississippi 39406, USA \\ ${ }^{3}$ United States Air Force Academy, Department of Chemistry and Chemistry Research Center Colorado 80840, USA \\ ${ }^{4}$ Aerospace Systems Directorate, Air Force Research Laboratory, Edwards AFB California 93524, USA

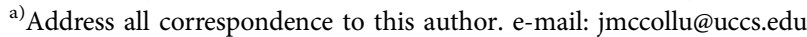 \\ b) Contributing Editor: Sarah Morgan \\ Received: 1 June 2020; accepted: 3 August 2020
}

Molecular weight $\left(M_{\mathrm{w}}\right)$ effects in poly(vinylidene fluoride) (PVDF) influence both processability and combustion behavior in energetic AI-PVDF filaments. Results show decreased viscosity in unloaded and fuel-lean (i.e., 15 wt\% Al) filaments. In highly loaded filaments (i.e., $30 \mathrm{wt} \% \mathrm{Al}$ ), reduced viscosity is minimal due to higher electrostatic interaction between Al particles and low $M_{\mathrm{w}}$ chains as confirmed by Fourier-transform infrared spectroscopy. Thermal and combustion analysis further corroborates this story as exothermic activity decreases in PVDF with smaller $M_{\mathrm{w}}$ chains. Differential scanning calorimetry and Thermogravimetric analysis show reduced reaction enthalpy and lower char yield in low $M_{\mathrm{w}}$ PVDF. Enthalpy reduction trends continued in nonequilibrium burn rate studies, which confirm that burn rate decreases in the presence of low $M_{\mathrm{w}}$ PVDF. Furthermore, powder X-ray patterns of post-burn products suggest that low $M_{\mathrm{w}}$ PVDF decomposition creates a diffusion barrier near the Al particle surface resulting in negligible $\mathrm{AlF}_{3}$ formation in fuel-rich filaments.

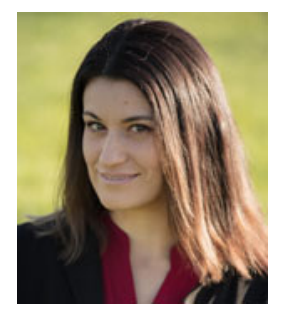

\begin{abstract}
Dr. Jena McCollum is an Assistant Professor and Director of the Additive Manufacturing Laboratory in the Department of Mechanical and Aerospace Engineering at the University of Colorado Colorado Springs. Prof. McCollum obtained her B.S. degree in Mechanical Engineering at West Texas A\&M University in 2012 and, subsequently, her Ph.D. in Mechanical Engineering at Texas Tech University in 2015 where she studied energetic materials. In 2016, she completed a National Research Council (NRC) Postdoctoral Research Fellowship at the United States Air Force Academy Chemistry Research Center where she studied polymer composite processing methods. Currently, her research interests include printing equipment design and material characterization to enhance polymer-based additive manufacturing technologies. Her current research interests include interfacial analysis of additively manufactured composites, manipulating binder formulations to achieve printability via extrusion-based methods, studying particle dynamics in thermosetting binders, and building a specialty additive manufacturing equipment to bridge technical gaps associated with composite design utilizing thermoplastic and thermosetting binders.
\end{abstract}

\section{Introduction}

In recent years, additive manufacturing (AM) has increased in popularity for a variety of fields requiring precise spatial composition and complex geometries. One such field that has gravitated toward these methods is energetics, specifically pyrolants and propellants, for on-demand fielded systems. Various AM methods from fused deposition modeling (FDM) [1,2] to direct ink writing (DIW) $[3,4,5]$ have been employed and demonstrated that, without the use of a suspending solvent, high nano aluminum ( $\mathrm{Al}$ ) loading (e.g., 25\%) is challenging in the melt without a processing aid. However, regardless of the printing method, one challenge that persists is ensuring processability of these sensitive materials.

The primary difference between the FDM and DIW lies in required feedstock viscosity (e.g., $0.1-10^{3} \mathrm{~Pa}$ s [6] for DIW and $>10^{3} \mathrm{~Pa} s$ for FDM). To apply AM methods to energetic 
materials requires incorporating high concentrations of reactive material to retain high reaction rates. Lower viscosities help to improve blending of reactive components within the energetic material matrix. To reduce viscosity, many groups have utilized binders that participate in the reaction $[1,2,4,7,8]$. Of these, poly(vinylidene fluoride) (PVDF) has shown excellent promise due to its high fluorine content (i.e., 59\%) as the oxidizing binder, well-characterized reaction decomposition mechanism $[9,10]$, and moderate melting temperature (i.e., $170{ }^{\circ} \mathrm{C}$ ) suitable for FDM [1, 2, 11, 12]. While the application explored here is energetic feedstocks, PVDF can be used both alone and blended with solid fillers in a variety of applications from electromagnetic shielding [13] to biomedical devices [11] to sensing materials [14].

To formulate energetic blends with AM processes, the link between PVDF viscosity and reaction kinetics needs further investigation. Energetic fillers tend to be shock sensitive, thus improving processing ease by dropping the viscosity would also improve processing safety. The strategy herein explores a variety of PVDF blends to investigate the impact of PVDF molecular weight $\left(M_{\mathrm{w}}\right)$ distribution and fuel loading on the reaction kinetics of Al-PVDF energetic filaments to aid in formulation.

\section{Results and Discussion}

\section{Apparent viscosity measurements}

As shown in Fig. 1, higher $M_{\mathrm{w}}$ PVDF results in decreased viscosities as a function of shear rate regardless of $\mathrm{Al}$ loading. The unloaded PVDF clearly show a decreasing viscosity trend from PVDF1 to PVDF3, which follows gel permeation chromatography (GPC) data shown in Fig. 2. The higher concentration of low $M_{\mathrm{w}}$ chains in PVDF3 acts as plasticizers, resulting in a low viscosity response.

At $15 \mathrm{wt} \% \mathrm{Al}$ loading, the increasing viscosity trend continues from PVDF3 to PVDF1. Interestingly, at $30 \mathrm{wt} \% \mathrm{Al}$ loading, PVDF2 exhibits the highest viscosity trend in this shear rate range. However, viscoelastic response in PVDF2 behaves in a more Newtonian manner than PVDF3, suggesting a further reduction of viscosity at higher shear rates. Viscosity increase with $\mathrm{Al}$ concentration is far less in PVDF1 blends than in PVDF2 or PVDF3, which suggests that $\mathrm{Al}$ particle aggregation is more significant in PVDF1. Therefore, at the high concentration of $30 \mathrm{wt} \% \mathrm{Al}$, a percolating network state might form which impedes chain relaxation motions, especially at higher shear rates. For PVDF2 and PVDF3 at $30 \mathrm{wt} \% \mathrm{Al}$, a percolation network is not observed at high shear rates because the particle-polymer interactions still dominate over particle-particle interactions, which reduces PVDF chain relaxations. Overall, the change in viscosity with $\mathrm{Al}$ loading is more dramatic as PVDF $M_{\mathrm{w}}$ decreases, due to stronger electrostatic
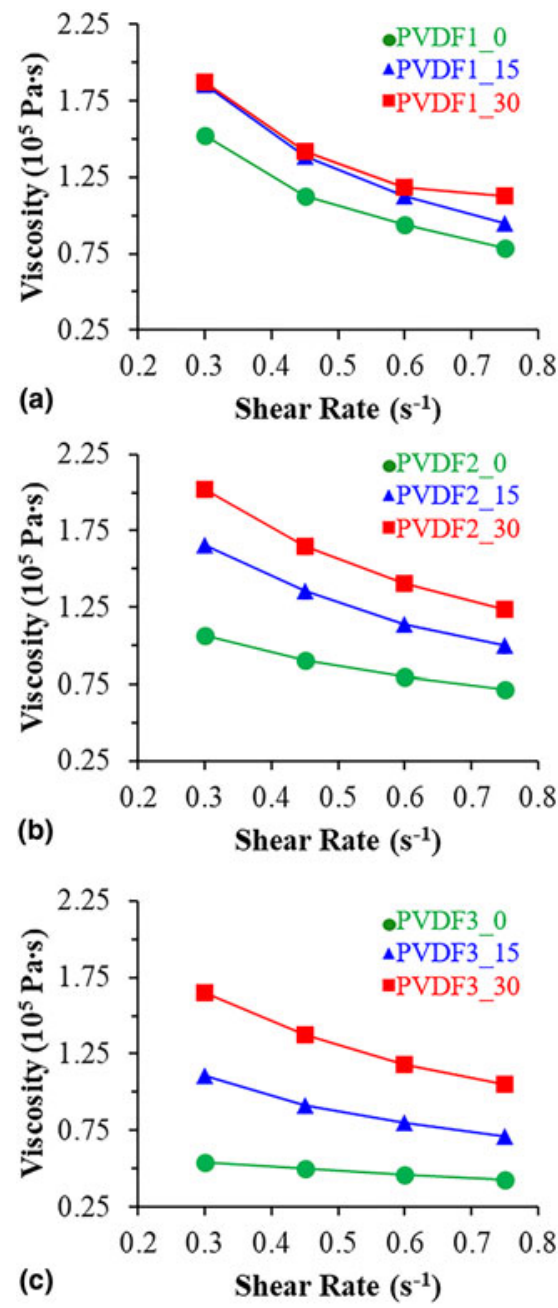

Figure 1: Viscosity response during compounding for unloaded and loaded (a) PVDF1, (b) PVDF2, and (c) PVDF3 samples.

interactions between PVDF and $\mathrm{Al}$ at lower $M_{\mathrm{w}}$, explored in more depth below.

\section{Gel permeation chromatography}

Figure 2 shows the GPC curves for each PVDF grade. Each PVDF grade shows higher $M_{\mathrm{w}}$ peaks in the range of 20$30 \mathrm{~min}$, as well as lower $M_{\mathrm{w}}$ peaks between 36 and $44 \mathrm{~min}$. Number and weight averaged $M_{\mathrm{w}}$ and dispersity values are shown in Table 1. Of the three, PVDF1 has the highest number and weight averaged $M_{\mathrm{w}}$ as well as lowest intensity peaks between 36 and $44 \mathrm{~min}$. Average $M_{\mathrm{w}}$ decreases and peak intensity of the low $M_{\mathrm{w}}$ species increases from PVDF1 to PVDF3, indicating increasing concentrations of low $M_{\mathrm{w}}$ PVDF fractions from PVDF1 to PVDF3. These results suggest that decreased viscosity from PVDF1 to PVDF3 as low $M_{\mathrm{w}}$ chains act as a plasticizer. Low $M_{\mathrm{w}}$ chains exhibit higher chain mobility than their large $M_{\mathrm{w}}$ counterparts that enables small $M_{\mathrm{w}}$ chains to 


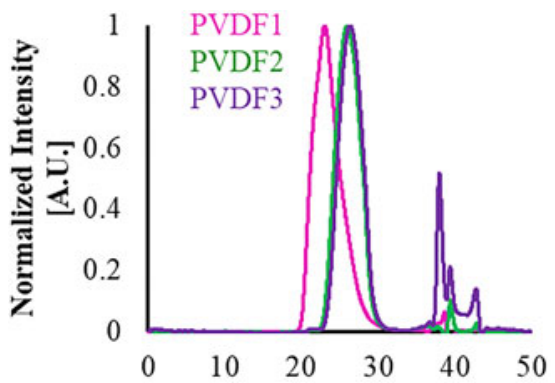

(a) Elution Time [min]

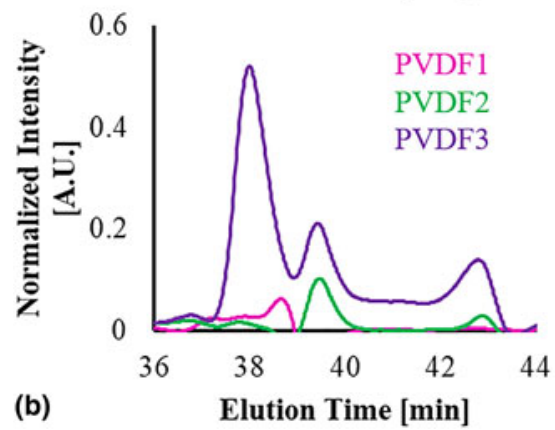

Figure 2: GPC curves for each PVDF grade where (a) shows the entire elution time and (b) shows an expanded view of higher elution time peaks.

penetrate high $M_{\mathrm{w}}$ regions and reduce large chain interactions with one another, which promotes plasticity in the PVDF.

\section{Fourier-transform infrared spectroscopy}

To evaluate Al-PVDF interactions, Fourier-transform infrared spectroscopy (FTIR) was performed. Figure 3 shows spectra for each filament in the range $700-1000 \mathrm{~cm}^{-1}$ at room temperature. Wavenumbers associated with peaks in the FTIR spectra in neat PVDF systems agree with literature values for alphacrystalline PVDF $[15,16]$. However, in the Al-loaded samples, distinct variations to the shapes and locations of these characteristic peaks are noted. The peak found at $763 \mathrm{~cm}^{-1}$ corresponds to $\mathrm{CF}_{2}$ bending, while the peak at $975 \mathrm{~cm}^{-1}$ arises from $\mathrm{CH}_{2}$ twisting vibration [17]. These wavenumbers are indicated by dashed lines in Fig. 3. The disruption of these two peaks suggest an interaction between $\mathrm{CF}$ dipoles in PVDF and surface charge on Al particles [2, 13]. While PVDF1 [Fig. 3(a)] experiences a slight deviation in these peaks in both location and amplitude, the peaks are still distinguishable. However, in PVDF2 [Fig. 3(b)] and PVDF3 [Fig. 3(c)], these

TABLE 1: Number $\left(\overline{M_{\mathrm{n}}}\right)$ and weight $\left(\overline{M_{\mathrm{w}}}\right)$ averaged molecular weights and dispersity index $(\nexists)$ for each of the PVDF grades.

\begin{tabular}{lllc}
\hline \hline Sample & $\overline{M_{\mathrm{n}}}(\mathrm{g} / \mathrm{mol})$ & $\overline{M_{\mathrm{w}}}(\mathrm{g} / \mathrm{mol})$ & Dispersity $\left(\bigoplus=\overline{M_{\mathrm{w}}} / \overline{M_{\mathrm{n}}}\right)$ \\
\hline PVDF1 & $2.18 \times 10^{5}$ & $8.91 \times 10^{5}$ & 4.09 \\
PVDF2 & $5.19 \times 10^{4}$ & $1.03 \times 10^{5}$ & 1.99 \\
PVDF3 & $4.38 \times 10^{4}$ & $8.31 \times 10^{4}$ & 1.89 \\
\hline \hline
\end{tabular}
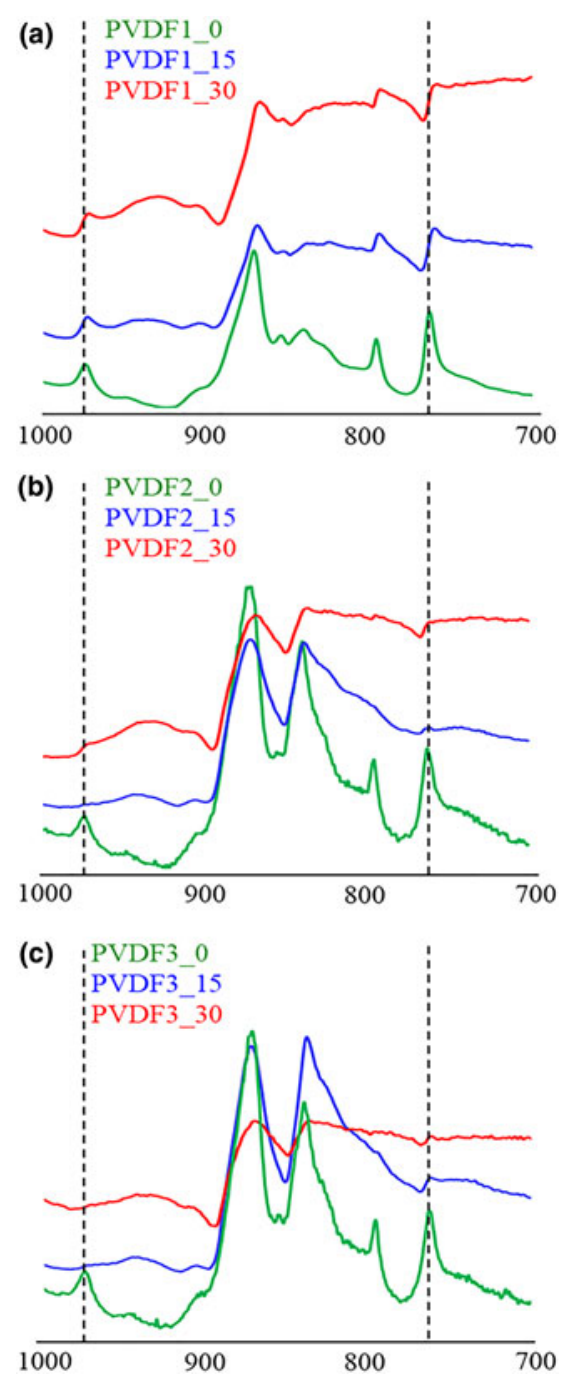

Figure 3: FTIR spectra for (a) PVDF1, (b) PVDF2, and (c) PVDF3 samples.

peaks are almost indistinguishable, suggesting that there is a stronger electrostatic-like interaction between PVDF and $\mathrm{Al}$ particle surface caused by increased chain mobility from low $M_{\mathrm{w}}$ PVDF chains interacting with the particle surface. Increased chain mobility can contribute to better adhesion at the Al-PVDF interface which aids in achieving a more homogeneous dispersion of the $\mathrm{Al}$ particles in the PVDF matrix and shorter diffusion distances during burning.

\section{Thermal analysis}

Differential scanning calorimetry (DSC) was used to study the effect of $M_{\mathrm{w}}$ on melting behavior and exothermic activity in each sample. An endothermic melting event is found for all samples between 155 and $165^{\circ} \mathrm{C}$ (see Table 2). Because $\alpha$ - and $\beta$-phase melting temperatures typically coincide at $167^{\circ} \mathrm{C}$ (with $\gamma$-phase around $179^{\circ} \mathrm{C}$ ) [18], DSC alone cannot distinguish between the crystalline phase at this heating rate. 
TABLE 2: Thermal data obtained via DSC/TGA for each specimen including melting temperature $\left(T_{\mathrm{m}}\right)$, melting enthalpy $\left(\Delta H_{\mathrm{m}}\right)$, crystallinity $\left(X_{\mathrm{c}}\right)$, reaction onset temperature $\left(T_{\mathrm{rxn}}\right)$, reaction enthalpy $\left(\Delta H_{\mathrm{rxn}}\right)$, char yield $(\mathrm{CY})$, and solid product formation $\left(x_{\mathrm{sp}}\right)$ as calculated by Eq. (1).

\begin{tabular}{lllllllll}
\hline \hline & $\begin{array}{l}T_{\mathrm{m}} \\
\left({ }^{\circ} \mathrm{C}\right)\end{array}$ & $\begin{array}{l}\Delta H_{\mathrm{m}} \\
(\mathrm{J} / \mathrm{g})\end{array}$ & $\begin{array}{l}X_{\mathrm{c}} \\
(\%)\end{array}$ & $\begin{array}{l}T_{\mathrm{rxn}} \\
\left({ }^{\circ} \mathrm{C}\right)\end{array}$ & $\begin{array}{l}\Delta H_{\mathrm{rxn}} \\
(\mathrm{J} / \mathrm{g})\end{array}$ & $\begin{array}{l}T_{\mathrm{d}} \\
\left({ }^{\circ} \mathrm{C}\right)\end{array}$ & $\begin{array}{l}\mathrm{CY} \\
(\%)\end{array}$ & $\begin{array}{l}X_{\mathrm{sp}} \\
(\%)\end{array}$ \\
\hline PVDF1_0 & 161 & -46.5 & 44 & - & - & 434 & 32 & 0 \\
PVDF1_15 & 162 & -34.7 & 39 & 364 & 922 & 369 & 61 & 19 \\
PVDF1_30 & 159 & -25.1 & 32 & 349 & 2728 & 359 & 79 & 27 \\
PVDF2_0 & 171 & -61.4 & 59 & - & - & 446 & 34 & 0 \\
PVDF2_15 & 168 & -54.0 & 60 & 273 & 623 & 369 & 58 & 16 \\
PVDF2_30 & 167 & -34.3 & 47 & 293 & 1282 & 367 & 68 & 16 \\
PVDF3_0 & 170 & -60.6 & 58 & - & - & 453 & 31 & 0 \\
PVDF3_15 & 170 & -51.7 & 58 & 278 & 660 & 370 & 58 & 16 \\
PVDF3_30 & 169 & -50.0 & 68 & 283 & 884 & 368 & 65 & 13 \\
\hline \hline
\end{tabular}

However, only representative peaks for $\alpha$-phase crystals were present in all sample FTIR spectra, which indicate that despite electrostatic interactions between $\mathrm{Al}$ and $\mathrm{CF}$ dipoles, $\mathrm{Al}$ particles have little impact on new crystalline phases. To assess the impact of $\mathrm{Al}$ loading on PVDF crystalline domains, crystallinity was calculated using Eq. (1), where $\Delta H_{\mathrm{m}}$ is the measured melting enthalpy of the blend (see Table 2), $\Delta H^{\star}{ }_{\mathrm{m}}$ represents the melt enthalpy of $100 \% \alpha$-crystalline PVDF (i.e., $104.5 \mathrm{~J} / \mathrm{g}$ $[18,19])$, and $\phi$ represents PVDF weight fraction [20].

$$
X_{\mathrm{c}}=\left(\Delta H_{\mathrm{m}} / \Delta H_{\mathrm{m}}^{*} \phi\right) \times 100 \%
$$

As shown in Table 2, crystallinity decreases for PVDF1 and PVDF2 in response to $\mathrm{Al}$ concentration, but increases for PVDF3. For PVDF1, Al particles hinder macromolecular chain mobility and prevent segments from obtaining an ordered alignment as $\mathrm{Al}$ concentration increases [21]. In PVDF2, hindered chain motion continues albeit less dramatically. Electrostatic interactions help to compatibilize the $\mathrm{Al}$, which leads to retained crystallization ability. However, in PVDF3 samples, particle loading aids crystal formation. Again, the presence of small PVDF chains compatibilize particles through electrostatic interactions between $\mathrm{Al}$ and PVDF. Furthermore, high concentration of low $M_{\mathrm{w}}$ chains promotes crystallization through enhanced chain mobility. While there is certainly interesting crystallization behavior here, the focus of this work lies in Al-PVDF interactions and the impact on combustion behavior.

At higher temperatures $\left(>250^{\circ} \mathrm{C}\right)$, exothermic events are observed in the DSC traces for all Al-loaded samples. In fuellean samples (i.e., $15 \mathrm{wt} \% \mathrm{Al}$ ), the combustion reaction enthalpy $\left(\Delta H_{\text {rxn }}\right)$ shows a moderately decreasing trend from PVDF1 [Fig. 4(a)] to PVDF3 [Fig. 4(c)]. However, in fuelrich samples (i.e., $30 \mathrm{wt} \% \mathrm{Al}$ ), reaction enthalpy decreases more dramatically from 2728 to $884 \mathrm{~J} / \mathrm{g}$ for PVDF1 to PVDF3, respectively. Reduced reaction enthalpy was
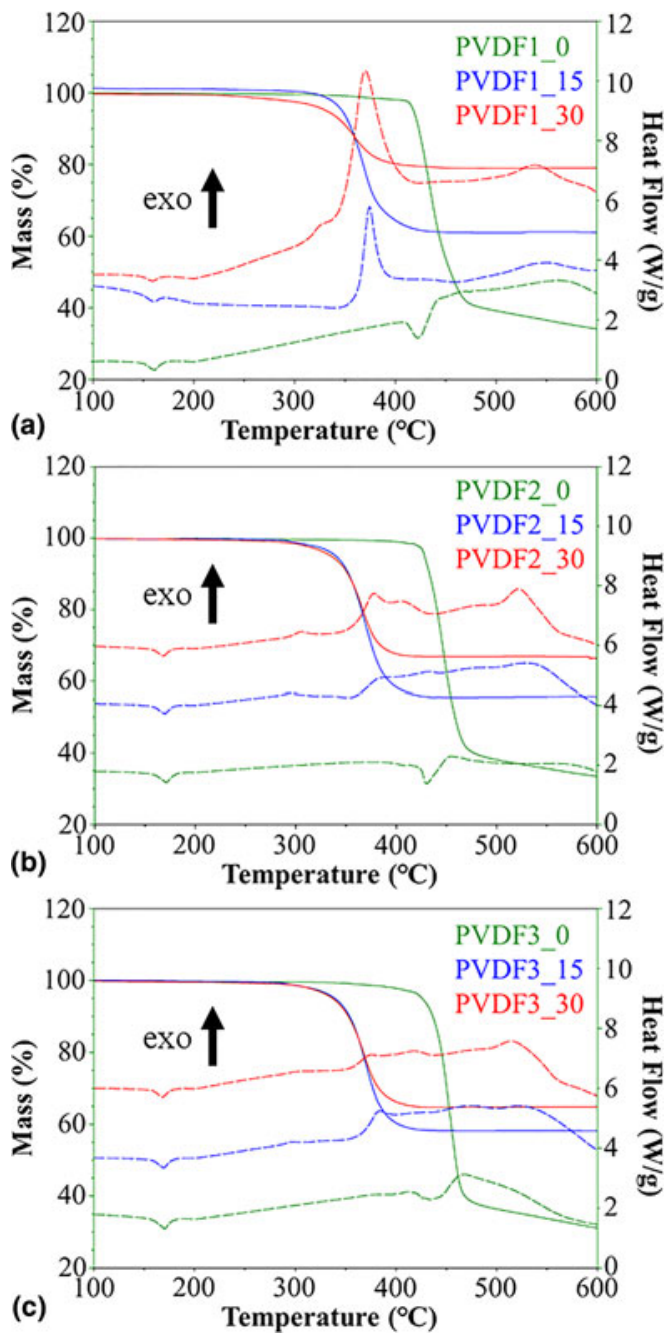

Figure 4: DSC/TGA traces for filaments comprised of (a) PVDF1, (b) PVDF2, and (c) PVDF3. TGA curves are solid and DSC curves are shown in dashes.

unexpected as Al-PVDF interfacial interactions are stronger as $M_{\mathrm{w}}$ decreases. Furthermore, in PVDF1, reaction onset temperature decreases from 364 to $349^{\circ} \mathrm{C}$ as $\mathrm{Al}$ content increases from 15 to $30 \mathrm{wt} \% \mathrm{Al}$, which occurs because higher Al loadings typically lead to lower temperature gas evolution that initiates the exothermic reaction between $\mathrm{Al}$ and PVDF $[2,7]$. Reduced reaction onset temperatures are not observed in PVDF2 or PVDF3 samples. In both cases, the onset of reaction shift to higher temperatures with Al loading. For all samples, the reaction enthalpy increases with $\mathrm{Al}$ loading, which occurs due to filament stoichiometry and is discussed at more length here [22].

Thermogravimetric analysis (TGA) shows unloaded PVDF experiences char yield between $31 \%$ and $34 \%$, which increases with higher $\mathrm{Al}$ concentrations. In loaded PVDF1 samples, char yield increases from $61 \%$ to $79 \%$ for 15 and $30 \mathrm{wt} \%$, respectively. The $18 \%$ increase in char yield from the $15 \mathrm{wt} \% \mathrm{Al}$ difference is due to reaction products between $\mathrm{Al}$ and PVDF 
decomposition intermediates. To account for the mass discrepancy, a weighted average of expected char yield $\left(x_{\text {avg }}\right)$ was calculated using Eq. (2), where CY is the char yield for the PVDF grade (see Table 2), $x_{\mathrm{Al}}$ is the weight fraction of $\mathrm{Al}$, and $x_{\mathrm{PVDF}}$ is the weight fraction PVDF.

$$
x_{\mathrm{avg}}=x_{\mathrm{Al}}+\mathrm{CY} \times x_{\mathrm{PVDF}}
$$

From here, $x_{\text {avg }}$ was subtracted from the measured char yield (CY) at $600{ }^{\circ} \mathrm{C}$. The difference represents solid reaction product formation at $600{ }^{\circ} \mathrm{C}$ (e.g., $\mathrm{AlF}_{3}, \mathrm{Al}_{2} \mathrm{O}_{3}$, or $\mathrm{Al}_{4} \mathrm{C}_{3}$ ) as shown in Eq. (3). (Note: $x_{\text {sp }}$ information is found in the last column of Table 2.)

$$
x_{\mathrm{SP}}=\mathrm{CY}-x_{\text {avg }}
$$

Interestingly, TGA shows char yield decreases for each loaded filament from PVDF1 to PVDF3, which result in mirrors the reaction enthalpy trends (i.e., with decreasing average $\left.M_{\mathrm{w}}\right)$. In PVDF1 samples, $\mathrm{x}_{\mathrm{sp}}$ increases with $\mathrm{Al}$ concentration. From previous studies [2,7], increased char yield is expected at higher $\mathrm{Al}$ concentration as a greater $\mathrm{Al}$ surface area more effectively retains fluorinated species by forming $\mathrm{AlF}_{3}$. Otherwise, these fluorinated species evolve as gaseous products. Furthermore, decomposition temperatures in PVDF1 filaments decrease with $\mathrm{Al}$ concentration. Again, decomposition temperatures decrease due to the increased $\mathrm{Al}$ surface area enhancing interactions between PVDF and $\mathrm{Al}$ at elevated temperatures leading to accelerated decomposition, and has been observed in previous work $[2,7]$.

In decreasing PVDF $M_{\mathrm{w}}$, reaction enthalpy trends deviate from previous studies. In PVDF1, $\Delta H_{\mathrm{rxn}}$ increases $296 \%$ from 15 to $30 \mathrm{wt} \% \mathrm{Al}$ loading. While PVDF2 samples also show an increasing $\Delta H_{\text {rxn }}$ with $\mathrm{Al}$ concentration, it only increases by $206 \%$ from 15 to $30 \mathrm{wt} \% \mathrm{Al}$ loading. PVDF3 shows the weakest response to $\mathrm{Al}$ loading with a reaction enthalpy increase of $134 \%$ from 15 to $30 \mathrm{wt} \% \mathrm{Al}$ loading. Reduced reaction enthalpy trends echo TGA data with no change in $x_{\mathrm{sp}}$ in PVDF2 filaments and a decrease in $x_{\text {sp }}$ in PVDF3 filaments with increased $\mathrm{Al}$ concentration. Furthermore, Al concentration shows a minimal impact on decomposition in PVDF2 and PVDF3 filaments. These results suggest that early in the PVDF2 and PVDF3 decomposition process, a diffusion barrier forms on the particle surface, which results in decreasing exothermic response that may be due to close proximity of low $M_{\mathrm{w}}$ PVDF chains on the $\mathrm{Al}$ surface, which form a char layer, preventing total combustion. Despite straightforward trends from DSC/TGA, nonequilibrium combustion behavior is needed to link these effects to practical use.

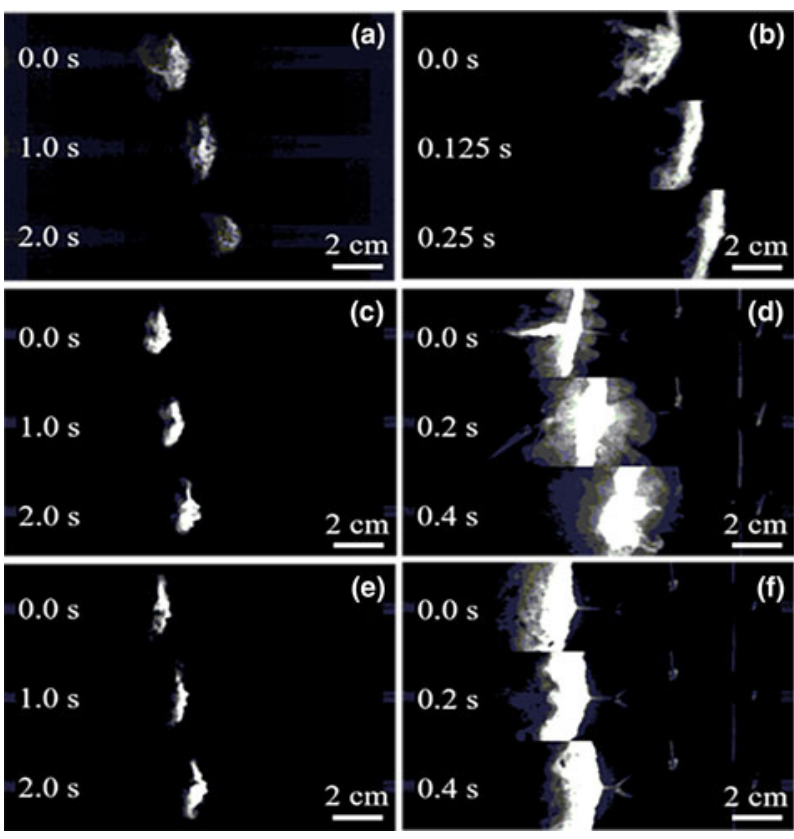

Figure 5: Still frames from the (a) PVDF1_15, (b) PVDF1_30, (c) PVDF2_15, (d) PVDF2_30, (e) PVDF3_15, and (f) PVDF3_30 burn videos.

\section{Combustion performance}

Much like the DSC/TGA trend, flame speeds favor higher $M_{\mathrm{w}}$ PVDF. Figure 5 shows still frames from high-speed video collection at designated time intervals for each sample (summarized in Table 3). All fuel-lean samples suggest PVDF grade minimally influenced burn rates, which reflects DSC/TGA results. However, fuel-rich burn rates decrease by $60 \%$ from PVDF1 to PVDF3, which further suggests that a solid reaction product may be formed in the combustion of low $M_{\mathrm{w}}$ PVDF that hinders exothermic behavior.

For more insight, char products from burn tests were examined via powder X-ray diffraction (XRD) (Fig. 6 shows the powder XRD patterns). In PVDF1, both fuel-rich and fuel-lean samples exclusively produce $\mathrm{AlF}_{3}$ which reflects previous work $[2,7]$. PVDF2 and PVDF3 fuel-lean char patterns also exclusively produce $\mathrm{AlF}_{3}$, which confirms low $M_{\mathrm{w}}$ PVDF does not significantly alter reaction behavior with low $\mathrm{Al}$ concentration. However, PVDF2 and PVDF3 fuel-rich patterns show $\mathrm{Al}_{2} \mathrm{O}_{3}$

TABLE 3: Linear burn rates $(\dot{x})$, average cross-sectional area $\left(A_{c}\right)$, and volumetric consumption rates $(\dot{V})$.

\begin{tabular}{lrcc}
\hline \hline Sample & \multicolumn{1}{c}{$\dot{x}(\mathrm{~cm} / \mathrm{s})$} & Average $A_{c}\left(\mathrm{~cm}^{2}\right)$ & $\dot{V}\left(\mathrm{~cm}^{3} / \mathrm{s}\right)$ \\
\hline PVDF1_15 & $1.3 \pm 0.19$ & $0.20 \pm 0.001$ & $0.26 \pm 0.001$ \\
PVDF1_30 & $12.7 \pm 0.70$ & $0.18 \pm 0.004$ & $2.23 \pm 0.003$ \\
PVDF2_15 & $1.2 \pm 0.01$ & $0.19 \pm 0.001$ & $0.23 \pm 0.000$ \\
PVDF2_30 & $10.6 \pm 0.66$ & $0.18 \pm 0.004$ & $1.91 \pm 0.003$ \\
PVDF3_15 & $1.4 \pm 0.03$ & $0.14 \pm 0.009$ & $0.20 \pm 0.000$ \\
PVDF3_30 & $5.6 \pm 0.08$ & $0.16 \pm 0.002$ & $0.90 \pm 0.000$ \\
\hline \hline
\end{tabular}




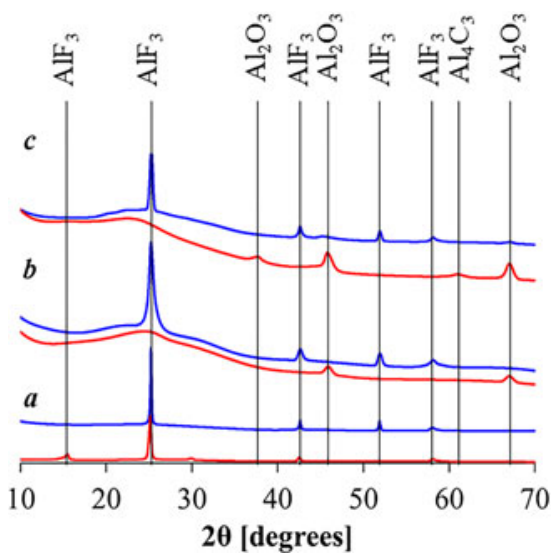

Figure 6: XRD spectra for (a) PVDF1, (b) PVDF2, and (c) PVDF3 burn products. Note: $30 \%$ loading is shown in red (bottom) and $15 \%$ loading is shown in blue (top) for each sample set.

and $\mathrm{Al}_{4} \mathrm{C}_{3}$ peaks which confirms reduced $\mathrm{AlF}_{3}$ formation. As mentioned above, the presence of low $M_{\mathrm{w}}$ PVDF likely reduces the formation of a percolated network at high $\mathrm{Al}$ concentration due to strong electrostatic interactions between the small PVDF chains and the particle surface. Furthermore, reduced percolation will influence the combustion performance as these reactions are highly conductive in nature. A reduced percolated Al network limits thermal transport as heat must pass through a poorly conductive polymer matrix, thus reducing reaction rates and combustion performance.

Upon heating, PVDF undergoes accelerated decomposition through interactions with the $\mathrm{Al}$ particle surface $[1,2,7,10]$. Thermal and combustion results suggest that in the presence of low $M_{\mathrm{w}}$ PVDF chains, decomposition products form near the $\mathrm{Al}$ particle surface which reduces combustion reaction efficiency by forming a diffusion barrier. Enhanced $\mathrm{AlF}_{3}$ formation improves combustion performance as $\mathrm{AlF}_{3}$ sublimates at a lower temperature (i.e., $760^{\circ} \mathrm{C}$ ) [23] compared to the melting temperatures of $\mathrm{Al}_{2} \mathrm{O}_{3}$ (i.e., $2030^{\circ} \mathrm{C}$ ) [24] or $\mathrm{Al}_{4} \mathrm{C}_{3}$ (i.e., $2160^{\circ} \mathrm{C}$ ) [25], which means that the diffusion barrier formed is weak and greater combustion takes place.

\section{Conclusions}

While processability increased with a reduction in PVDF $M_{\mathrm{w}}$ in unloaded and fuel-lean filaments, viscosity reduction in highly loaded filaments (i.e., $30 \mathrm{wt} \% \mathrm{Al}$ ) is minimal, at best. Sub-par viscosity reduction is due to higher electrostatic interaction between $\mathrm{Al}$ particles and low $M_{\mathrm{w}}$ chains as confirmed by FTIR, which eliminates the plasticizing effect of these chains as seen in lower-loaded filaments. Thermal and combustion analysis further corroborates this story as exothermic activity decreases in PVDF with smaller $M_{\mathrm{w}}$ chains. DSC and TGA show reduced reaction enthalpy and lower char yield in low $M_{\mathrm{w}}$ PVDF. Reduced reaction rates were also noted in nonequilibrium burn rate studies, which confirm that burn rate decreases in the presence of low $M_{\mathrm{w}}$ PVDF. Furthermore, powder X-ray patterns of post-burn products suggest low $M_{\mathrm{w}}$ PVDF decomposition creates a diffusion barrier near the $\mathrm{Al}$ particle surface resulting in negligible $\mathrm{AlF}_{3}$ formation in fuel-rich filaments.

Findings from this study provide insight to formulation strategies in energetic composites, particularly those formulated for AM methods. Although low $M_{\mathrm{w}}$ plasticizing effects may be useful in improving AM feasibility, particle interfaces must be protected from low $M_{\mathrm{w}}$ char products, which reduce energetic effectiveness.

\section{Experimental Section}

\section{Materials}

Three PVDF grades were used in this study. Grade 1 was obtained from Alfa Aesar (Tewksbury, MA, USA) and arrived in powder form. Grades 2 and 3 were received from Arkema (Kynar 710 and Kynar 705) and arrived in pellet form. Aluminum nanopowder (Armament Research Development and Engineering Center (ARDEC)) with an average particle size of $80 \mathrm{~nm}$ and a specific surface area of $25 \mathrm{~m}^{2} / \mathrm{g}$ were used as a fuel. The nanopowder has $75 \%$ active $\mathrm{Al}$ content by mass. All materials were used as-received. Filament designation is given by PVDF grade and particle loading with PVDF1_XX, PVDF2_XX, and PVDF3_XX designating Alfa Aesar, Kynar 710, and Kynar 705, respectively. For example, filaments made with Kynar 710 and $30 \mathrm{wt} \% \mathrm{Al}$ are designated as "PVDF2_30".

\section{Sample preparation}

Blends were weighed dry and hand mixed for $5 \mathrm{~min}$. The mixture was manually fed into a Thermo Scientific HAAKE Minilab II (Waltham, MA) and compounded at $190{ }^{\circ} \mathrm{C}$ and 50 RPM. After the entire mixture was fed into the compounder, it was mixed at incrementally higher screw speeds $(50,75,100$, and 125 RPM). The mixture was compounded at each speed until the pressure difference between two pressure transducers inside the compounder chamber held constant. The blends were then extruded at 50 RPM to form filament approximately $2 \mathrm{~mm}$ in diameter.

\section{Apparent viscosity measurements}

Apparent viscosity was measured in situ by monitoring the pressure transducers in the wall of the HAAKE minilab. Pressure data was taken at each transducer for $1 \mathrm{~min}$ at screw speeds $(\omega)$ of $50,75,100$, and 125 RPM using the HAAKE minilab software and exported to an excel file. The difference 
between these two pressures was used in viscosity calculations. Equation (4) is used to calculate apparent viscosity, where $\eta, \tau$, and $\dot{\gamma}$ represent viscosity, shear stress, and shear rate, respectively.

$$
\eta=\tau / \dot{\gamma}
$$

Shear stress at the wall was calculated using Eq. (5), where $h$ and $w$ represent the height and width of the channel (i.e., 1.5 and $10 \mathrm{~mm}$, respectively), $\Delta L$ represents the distance between the pressure transducers, and $\Delta P$ represents the pressure differential.

$$
\tau=h \times w \times \Delta P / 2 \times(h+w) \times \Delta L .
$$

Finally, the shear rate was calculated using Eq. (6) where $\omega$ represents screw speed.

$$
\dot{\gamma}=2(h+w) \times \omega / 60 \times \Delta L .
$$

\section{Gel permeation chromatography}

GPC was performed using a Waters Alliance 2695 separations module, an online multiangle laser light scattering (MALLS) detector fitted with a gallium arsenide laser $(20 \mathrm{~mW})$ operating at $658 \mathrm{~nm}$ (miniDAWN TREOS, Wyatt Technology Inc.), an interferometric refractometer (Optilab T-rEX, Wyatt Technology Inc.) operating at $65^{\circ} \mathrm{C}$, and $685 \mathrm{~nm}$, and two PLgel MIXED-E columns (Polymer Laboratories Inc.) in series (pore size $50-103 \AA$, $5 \mu \mathrm{m}$ bead size). The mobile phase was $0.02 \mathrm{M} \mathrm{LiBr} / \mathrm{DMF}$ delivered at a flow rate of $0.5 \mathrm{~mL} / \mathrm{min}$. The polymer samples were pre-dissolved in $0.02 \mathrm{M} \mathrm{LiBr} / \mathrm{DMF}$ by stirring for $1 \mathrm{~h}$ at $60{ }^{\circ} \mathrm{C}$. The injection volume was set at $100 \mu \mathrm{L}$. The detector signals were simultaneously recorded using ASTRA software (Wyatt Technology Inc.), and absolute $M_{\mathrm{w}}$ was determined by MALLS using a $\mathrm{d} n / \mathrm{d} c$ value obtained from the interferometric refractometer response, assuming $100 \%$ mass recovery from the columns.

\section{Fourier-transform infrared spectroscopy}

To observe Al-PVDF interfacial behavior, PVDF crystalline phases were identified using FTIR spectroscopy. Absorption spectra were collected using a Thermo Scientific FTIR-ATR Nicolet iS10 (Waltham, MA). A background spectrum was collected before each sample scan. Sample spectra were collected in the range of $600-1600 \mathrm{~cm}^{-1}$ averaged from 64 scans with a $2 \mathrm{~cm}^{-1}$ spectral resolution.

\section{Thermal analysis}

Thermal analysis was performed using a TA Instruments Q600 simultaneous DSC and TGA (SDT) (New Castle, DE). Samples were heated at a rate of $5{ }^{\circ} \mathrm{C} / \mathrm{min}$ from 30 to $700{ }^{\circ} \mathrm{C}$ under a constant flow of argon $(25 \mathrm{~mL} / \mathrm{min})$. Samples of approximately $5 \mathrm{mg}$ were placed into an alumina crucible and loaded into the SDT.

\section{Burn characterization}

Burn testing was performed on as-extruded filament specimens. High-speed videos were captured on a Phantom v7.3 high-speed camera (Wayne, NJ) at a sample rate of $1000 \mathrm{fps}$ with an exposure of $10 \mu \mathrm{s}$ and an extreme dynamic range (EDR) of $5 \mu$ s. Samples were attached on a ring stand, enclosed in an acrylic barrier, and ignited at one end with a propane torch. Flame speeds were calculated by recording flame from pixel position at designated time intervals, then converting to $\mathrm{cm} / \mathrm{s}$ using a calibration image.

\section{X-ray diffraction}

XRD measurements were completed by the Bragg-Brentano focusing method on a Rigaku SmartLab X-ray diffractometer (The Woodlands, TX) with a $\mathrm{Cu} \mathrm{K}_{\alpha}$ radiation source and a $\mathrm{Cu} \mathrm{K}_{\beta}$ filter at an operating voltage and current of $40 \mathrm{kV}$ and $30 \mathrm{~mA}$, respectively. Measurement profiles were collected from $5^{\circ}$ to $70^{\circ}$ in continuous scan mode at $3 \% \mathrm{~min}$ with a step width of $0.01^{\circ}$ on a $\theta / 2 \theta$ scan axis. The post-burn soot was tightly packed into a glass sample holder and loaded into the XRD after optic calibration. Sample alignment was performed prior to each sample data collection.

\section{Acknowledgments}

The authors thank Dr. Geoff McHarg (Space Physics and Atmospheric Research Center (SPARC), United States Air Force Academy) for the high-speed camera for burn rate measurements. The authors also thank Jim Goldbach from Arkema for generously donating the Kynar PVDF grades and Dr. Christopher Crouse for supplying the nano aluminum powder. J.M.M. and J.E.M. acknowledge the Joint Insensitive Munitions Program (JIMTP) for funding. S.T.I. acknowledges Air Force Office of Scientific Research (AFOSR) for partial funding.

\section{References}

1. T.J. Fleck, A.K. Murray, I.E. Gunduz, S.F. Son, G.T.C. Chiu, and J.F. Rhoads: Additive manufacturing of multifunctional reactive materials. Addit. Manuf. 17, 176 (2017).

2. J.A. Bencomo, J.M. McCollum, and S.T. Iacono: 3D printing multifunctional fluorinated nanocomposites: Tuning electroactivity, rheology and chemical reactivity. J. Mater. Chem. A 6, 12308 (2018). 
3. X. Zhou, M. Torabi, J. Lu, R. Shen, and K. Zhang:

Nanostructured energetic composites: Synthesis, ignition/combustion modeling, and applications. ACS Appl. Mater. Interfaces 6, 3058 (2014).

4. F.D. Ruz-Nuglo and L.J. Groven: 3-D printing and development of fluoropolymer based reactive inks. Adv. Eng. Mater. 20, 1 (2018).

5. H. Wang, M. Rehwoldt, D.J. Kline, T. Wu, P. Wang, and M.R. Zachariah: Comparison study of the ignition and combustion characteristics of directly-written $\mathrm{Al} / \mathrm{PVDF}, \mathrm{Al} / \mathrm{Viton}$ and $\mathrm{Al} /$ THV composites. Combust. Flame 201, 181 (2019).

6. L. Li, Q. Lin, M. Tang, A.J.E. Duncan, and C. Ke: Advanced polymer designs for direct-ink-write 3D printing. Chemistry 25, 10768 (2019).

7. J. McCollum, A.M. Morey, and S.T. Iacono: Morphological and combustion study of interface effects in aluminized poly(vinylidene fluoride) composites. Mater. Des. 134, 64-70 (2017).

8. C. Huang, G. Jian, J.B. DeLisio, H. Wang, and M.R. Zachariah: Electrospray deposition of energetic polymer nanocomposites with high mass particle loadings: A prelude to $3 \mathrm{D}$ printing of rocket motors. Adv. Eng. Mater. 17, 95 (2014).

9. Z-X. Xu, C-X. Zhang, Z-X. He, and Q. Wang: Pyrolysis characteristic and kinetics of polyvinylidene fluoride with and without pine sawdust. J. Anal. Appl. Pyrolysis 123, 402 (2017).

10. J. B. Delisio, C. Huang, G. Jian, M. R. Zachariah, and G. Young: Ignition and reaction analysis of high loading nano- $\mathrm{Al} /$ fluoropolymer energetic composite films. In American Institute of Aeronautics and Astronautics, National Harbor, Maryland (2014); pp. 1-8. https://doi.org/10.2514/6.2014-0646

11. E. Suaste-Gómez, G. Rodríguez-Roldán, H. Reyes-Cruz, and O. Terán-Jiménez: Developing an ear prosthesis fabricated in polyvinylidene fluoride by a $3 \mathrm{D}$ printer with sensory intrinsic properties of pressure and temperature. Sensors 16, 1 (2016).

12. H. Kim, F. Torres, Y. Wu, D. Villagran, Y. Lin, and T-L. Tseng: Integrated 3D printing and corona poling process of PVDF piezoelectric films for pressure sensor application. Smart Mater. Struct. 26, 085027 (2017).

13. J. Arranz-Andrés, N. Pulido-González, C. Fonseca, E. Pérez, and M.L. Cerrada: Lightweight nanocomposites based on poly(vinylidene fluoride) and $\mathrm{Al}$ nanoparticles: Structural, thermal and mechanical characterization and EMI shielding capability. Mater. Chem. Phys. 142, 469 (2013)

14. K. Fu, Y. Yao, J. Dai, and L. Hu: Progress in 3D printing of carbon materials for energy-related applications. Adv. Mater. 29, 1603486 (2017)

15. Y. Okabe, H. Murakami, N. Osaka, H. Saito, and T. Inoue: Morphology development and exclusion of noncrystalline polymer during crystallization in PVDF/PMMA blends. Polymer 51, 1494 (2010).

16. A. Gebrekrstos, M. Sharma, G. Madras, and S. Bose: New physical insights into shear history dependent polymorphism in poly(vinylidene fluoride). Cryst. Growth Des. 16, 2937 (2016).

17. Y. Bormashenko, R. Pogreb, O. Stanevsky, and E. Bormashenko: Vibrational spectrum of PVDF and its interpretation. Polym. Test. 23, 791 (2004).

18. I.S. Elashmawi and N.A. Hakeem: Effect of PMMA addition on characterization and morphology of PVDF. Polym. Eng. Sci. 48, 895 (2008).

19. M. Lee, T. Koo, S. Lee, B.H. Min, and J.H. Kim: Morphology and physical properties of nanocomposites based on poly(methyl methacrylate)/poly(vinylidene fluoride) blends and multiwalled carbon nanotubes. Polym. Compos. 36, 1195 (2015).

20. L. Wang and S. Chen: Crystallization behaviors of poly(vinylidene fluoride) and poly(methyl methacrylate)-block-poly(2-vinyl pyridine) block copolymer blends. J. Therm. Anal. Calorim. 125, 215 (2016)

21. W. Zhou, J. Zuo, and W. Ren: Thermal conductivity and dielectric properties of Al/PVDF composites. Compos. A Appl. Sci. Manuf. 43, 658 (2012).

22. J.W. Strutton, M.C. Knott, J.A. Bencomo, S.T. Iacono, J.E. Mates, J.R. Alston, and J.M. McCollum: Particle size effects in manipulating polymer decomposition to alter burn performance in aluminum/PVDF filaments. Polym. Int. (2020). In Review.

23. P.E. Rosenberg: Stability relations of aluminum hydroxy-fluoride hydrate, a ralstonite-like mineral, in the system $\mathrm{AlF}_{3}-\mathrm{Al}_{2} \mathrm{O}_{3}-\mathrm{H}_{2} \mathrm{O}-$ HF. Can. Mineral. 44, 125 (2006).

24. R.F. Geller and P.J. Yavorsky: Melting point of alpha-alumina. J. Res. Natl. Bur. Stand. 34, 395 (1945).

25. C. Qiu and R. Metselaar: Solubility of carbon in liquid $\mathrm{Al}$ and stability of $\mathrm{Al}_{4} \mathrm{C}_{3}$. J. Alloys Compd. 216, 55 (1994). 